-ORIGINAL ARTICLE-

Volume 13 lssue 42021

DOI: 10.21315/eimj2021.13.4.3

ARTICLE INFO

Received: 20-05-2020

Accepted: 12-07-2021

Online: 30-12-2021

\section{Role of Community Placement Programmes in Development of Professional Basic Skills Among First-Year Medical Students}

\author{
Mohd Zarawi Mat Nor, Nik Mohd Rizal Mohd Fakri, Muhamad Saiful \\ Bahri Yusoff, Ahmad Fuad Abdul Rahim, Mohamad Najib Mat Pa, \\ Muhd Al-Aarifin Ismil, Jamillah Al-Muhammady Mohammad, \\ Rosniza Ab Aziz
}

Department of Medical Education, School of Medical Sciences,

Universiti Sains Malaysia, Kelantan, MALAYSIA

To cite this article: Mat Nor MZ, Mohd Fakri NMR, Yusoff MSB, Abdul Rahim AF, Mat Pa MN, Ismil MAA, Mohammad JAM, Ab Aziz R. Role of community placement programmes in development of professional basic skills among first-year medical students. Education in Medicine Journal. 2021;13(4):33-42. https://doi.org/10.21315/eimj2021.13.4.3

To link to this article: https://doi.org/10.21315/eimj2021.13.4.3

\begin{abstract}
Various methods have been implemented in the medical field to foster professional basic skills among students. Nevertheless, the contribution of a community placement programme (CPP) with regard to first year of medical students is still unclear. The study objective is to explore how CPP contributes to the development of professional basic skills among students within this group. This qualitative study was conducted between January 2017 and March 2018. Two batches of the first-year medical students with a total of 24 students were involved in the study. The data were gathered using reflective journals which were written from a one-day English camp that was held at the Universiti Sains Malaysia's School of Medical Sciences. A total of 24 reflective journals have been used as data sources which were then analysed using ATLAS.ti software version 8.0 based on the open, axial and selective coding process. The result has shown that professional skills were established through three themes and eight categories. The themes were personal skills (e.g., time management, self-management, self-confident, social adjustment, internal motivation and communication skill), leadership skills (e.g., teamwork) and scientific skills (e.g., proposal writing skills). CPP is an agenda to nurture the medical students' professional basic skills. Therefore, such an agenda must continue to be included in medical education.
\end{abstract}

Keywords: Professional basic skill, Community placement programme, Early phase of medical students, Public Malaysian medical school, Qualitative study Sciences, Health Campus, Universiti Sains Malaysia, 16150 Kubang Kerian, Kelantan, Malaysia

Email: nrizal@usm.my 


\section{INTRODUCTION}

Community-based education (CBE) is a structured programme with the objective of promoting participants' learning and social development, particularly through a systematic activity that involves a group of selected community (1). One of the activities in CBE is the community placement programme (CPP) (2). Simply put, the CPP is an outdoor activity that relates to society and introduced to first-year medical students. The purpose of the CPP is to provide a specific platform to the medical students in order to expand their knowledge and skills through an interactive session with a selected group, such as students, orphans and others (3). Evidence from literature has shown that the CPP is essential in providing basic professional skills for medical students. It includes leadership, teamwork and collaboration skills among participants.

Thus, CPP is regarded as an effective mechanism for the nature and nurture practices towards students' professional basic skills in medical education. This is due to the fact that the medical education field is not simply about accomplishing a high level of subject matter; rather, it also promotes students' development of professional skills such as time management, self-management, teamwork and leadership (4). The methods in which medical students establish proficient features has significant consequences for their capability as excellent medical students. Hence, various agendas are integrated into the medical curriculum, including the CPP (5).

Since the establishment of the Universiti Sains Malaysia (USM) in 2007, the CPP was introduced (6) with the aim of exposing students to professional knowledge and skills (6-7). The programme began with the dividing of students into groups. Each group consisted of 8 to 10 students, and each group was supervised by a supervisor who was assigned along with the lecturers. Each group was responsible for planning, managing and evaluating the proposed programmes or activities. Among the activities conducted was the sharing of experiences and thoughts, games and donation. Before initiating the activity, participants were required to present the proposal to their supervisor for evaluation and approval.

In the context of the present study, two series of one-day English motivational camps with the theme "Let's Talk" were conducted at the School of Medical Sciences, USM between January 2017 and March 2018. A total of 60 form four secondary school students participated in the motivational camp.

Many studies have been conducted on similar CPP. The results have shown that such programmes have contributed to positive impact on the basic professional skills of medical students, especially those in their clinical year. It has also been recognised as an effective mechanism in enhancing professionalism characteristics for such groups. Despite the positive impact of these aspects, no recent comprehensive studies have been conducted to date in the exploration of real CPP experiences among first-year medical students. This situation has led to a lack of current accurate information on the experience of CPP in regard to these groups of students. Further information on this experience is vital, as it may potentially be the main point from which future enhancement of such a programme will begin.

A plethora of literature reviews have intensively discussed CPP. These reviews are not limited specifically to the medical education field but others as well. The discussion can be categorised into two aspects, namely effectiveness and contribution to professional skills (6). Professional skill is referred to as a high skill of competency needed in performing a specific task. In a previous study, it was found that CPP has significantly contributed to university students' competencies in policy development, programme planning, communication and community dimensions 
of practice. In a quantitative study aimed at evaluating the effectiveness of CPP, it was found that CPP positively impacted skills of leadership, communication and teamwork components $(6,8)$. In the context of doctors' professional basic skills, almost all studies have discussed the impact of nonclinical activities on professionalism matters.

Social adjustment, leadership skills and management, teamwork, hands-on skills and creativity are components that represent professional development (9). Based on this finding, the researcher concluded that these elements are vital in shaping professional skills among medical graduates who are balanced with knowledge, skills, upright behaviour and values. A similar result has been shown in a study done in Canada, where it was seen that CPP had the ability to enhance mental health and the well-being qualities of medical students (10).

A study conducted in Australia found that CPP were important not only to enhance students' communication skills but also to affect concern and recognition of the nonmedical health provision facilities in local societies.

In a similar study, researchers focused on the Community and Family Case Study (CFCS) programme to foster professional identity development (11). The results indicated that the CFCS programme had successfully nurtured appropriate personal identity through the development of professional basic skills, soft skills, research skills and personal values. Evidence from previous literature has shown that CPP are essential to providing basic professional skills for medical students, including leadership, teamwork and collaboration skills. These skills were developed through personal experiences while conducting activities related to their study.

Thus, research efforts aimed at exploring students' experiences on the matter are timely and relevant. Interestingly, researchers had attempted to understand this aspect via the participants' lens, particularly those who were involved in such activities at a full-time rate. The entire study revolves around the answer to the research questions concerning how CPP contribute to the professional basic skills among firstyear medical students. The study objective is to understand how such programmes contribute to professional basic skills among medical students.

\section{MATERIALS AND METHODS}

A phenomenological study design was carried out to explore how CPP contribute to medical students' professionalism. It was defined as the skills, good judgement and polite behaviour expected from a person who is trained to do a job well. This type of design was chosen based on the following justifications:

a. Using a small sample size.

b. Exploring how people experience a particular situation in the context of the study (i.e., faculty development programme).

c. Using in-depth interviews to collect the data.

d. Practising open-ended questions to allow the participants to fully describe their own viewpoints (12).

A total of 24 first-year medical students (12 students from the 2017 and 2018 intake, respectively) were required to partake in the event. Two of the participants were involved as speakers, while others conducted small group activities. There were 24 self-reflection journals (SRFJ) available as sources of the sample data. The estimated sample size was based on achieving a data saturation point. Data saturation is reached when there is enough information to replicate the study (13), when the ability to obtain additional new information has been attained (14), and when further coding is no longer feasible (14). Ethical approval was sought 
and obtained from the Human Ethics Committee of USM prior to the data collection process.

SRFJ uses reflective journal writing as a form of document analysis, and this method was used to gather the medical students' experiences related to professionalism features during their involvement in a oneday English motivational camp. SRFJ is a way of collecting data that essentially involves the engagement of a small number of people. Prior to the data collections, the study participants were given a short briefing about the procedure on the SRFJ writing which consisted of critical appraisal, peer group discussion and selfawareness to self-evaluation. In the first step, participants were given the freedom to share descriptions and emotional reactions of their experiences in no specific format. The second step involved discussion among students about what was performed in the first step. The last step of the reflective process was accomplished independently by the participants following the postactivity meeting. In the reflective journal writing, participants were expected to file unique features of their own learning as an outcome of group discussion. This is the last step of analysis which proves the student's capability to be self-reflective in the form of written documentation.

The journal reflection writing process was completed in the School of Medical Sciences from the 1st to 30th January 2017 and 1st to 30th March 2018 following completion of these activities. As a result, a total of 24 journals were provided at the end of the session. Each journal was labelled with a specific code. For instance, the code JR1-5/1/2017, JR1 referred to Journal 1 , with $5 / 1 / 2017$ as the date of journal collection (5th January 2017).

Validity and reliability are two factors that any qualitative researcher should be concerned about, particularly when designing a study, analysing results and judging the quality of the study (15). In qualitative paradigms the terms credibility, transferability, dependability and conformability are to be the essential criteria for quality.

One of the key criteria addressed by positivist researchers is that of internal validity, in which researchers seek to ensure that their study measures or tests are what is intended. This study used member checking as a tool to ensure its credibility. Member checks can assist qualitative researchers by allowing participants to review and clarify the journal and interpretations to validate the accuracy of the participants' ideas. Maykut and Morehouse found that members' feedback is very valuable and at times may help researchers see or emphasise something that is amiss (16). In this study, participants were requested to check and verify the journal content as soon as the journal was collected. Feedback from participants were considered to correct the data, further improving the data's credibility.

To achieve transferability, researchers used thick descriptions of the contexts, processes, participants and findings from the current study and allowed readers to transfer the collected and analysed information to similar settings. The transferability and generalisability of the data was expanded by having participants in this study from different cohorts and different cultural backgrounds. An array of data collection methods were used in addition to a variety of tests for validity and reviews of the literature. For this reason, research finding generalisability is supported.

In addressing the issue of reliability, the positivist employs techniques to show that similar results would be obtained if the work was repeated in the same context with the same methods and the same participants (17). Thus, the research design may be viewed as a "prototype model". Such indepth coverage also allows the reader to assess the extent to which proper research practices have been followed. In order to enable readers of this research report to develop a thorough understanding of the 
methods and their effectiveness, researchers have included the following sections:

a. The research design and its implementation, describing what was planned and executed on a strategic level.

b. The operational detail of data gathering of what was performed in the field.

The concept of conformability is the qualitative investigator's comparable concern to objectivity. Steps must be taken to ensure that the work's findings are the results of the informants' experiences and ideas rather than the characteristics and preferences of the researcher (17).

A detailed methodological description enables the reader to determine the extent to which the data and constructs emerging from it may be accepted. This process is termed as an "audit trail", which allows any observer to trace the course of the research step-by-step via decisions made and procedures described.

A qualitative approach to data analysis entails identifying themes and constructing ideas as they emerge in an attempt to reduce the data into codes or categories (18). Journals from various groups of participants (2017 and 2018) were combined into one set and analysed using a grounded theory approach. This method, much like phenomenology, seems to be the most appropriate in drawing out participants' personal meanings of how English motivational camp experiences to contribute to their professionalism features. Grounded theory data analysis encompasses the reduction of data into three procedures, namely open coding, axial coding and selective coding (19). The analysis process was completed using the ATLAS.ti software version 8.0, allowing the researcher to manage "narrative data by coding, indexing passages of text, labelling categories of text, and retrieving the labelled passages across all cases".
Open coding is the process of reducing the collected data into initial themes or categories. This step in the coding process occurs through a close examination of the data to produce concepts, themes and ideas that correspond to the data. During open coding, data is sorted into emerging themes and compared for similarities and differences (19). From this point, categories of information are developed to aid in the research of the phenomenon being studied (20).

Once initial themes and categories are discovered, the researcher begins the next phase of data analysis, or axial coding. In axial coding, similar concepts or themes are linked together to identify a single category based on their homogeneous conditions within similar contexts (19). Axial coding consists of the researcher breaking one category into subcategories and comparing the interrelationships among that category (20). In this phase, the researcher asked questions about the meaning of the data and emerging concepts, and comparisons were made continuously to differentiate data and concepts throughout the study.

The last phase in the coding process consists of identifying specific core categories from the categories discovered in the axial coding phase. Selective coding is the phase of selecting the core category, systematically comparing it to other categories and forming those connections (21). During selective coding, a story is built that connects the subcategories and categories around the core category (20). Relationships against the collected data are validated.

\section{RESULTS}

A total of 24 participants participated in the study, of which 16 (67\%) were male and $8(33 \%)$ were females. A total of 16 (67\%) participants were of Malay ethnicity with $5(21 \%)$ and $3(12 \%)$ of Chinese and Indian ethnicity, respectively. Overall, there were three themes and eight categories. The themes were personal skills (e.g., 
time management, self-management, selfconfident, social adjustment, internal motivation and communication skills), leadership skill (e.g., teamwork) and scientific skills (e.g., proposal writing) (see Table 2).

\section{Theme 1: Personal Skills}

Self-development occurs over the course of an individual's entire life. The first theme (personal skills) consists of six categories. The following are detailed explanations on such categories.

\section{Category 1: Time management}

We have allocated two weeks for planning and evaluating the proposed project. So, we need to manage time well. (JR1-2/2/2017)

Whatever happens we need to finish (the project) in the period of two weeks. (JR8-3/2/2017)

\section{Category 2: Self-management}

One of the benefits of the programmes is self-management, whereby our team must... fully [consider] the best way to manage our self before, [during] and after the programme [is] completed. (JR7-2/2/2017)

\section{Category 3: Self-confident}

Handling [meetings] and [discussions] were among the activities which were done during the programme...from this we have explored many things, including [self-confidence]. Before this, I [suffered from] anxiety (panic anxiety), but now...I [feel that] I am healthier and stronger than before. (JR17-2/2/2017)

\section{Category 4: Social adjustment}

Consistent with the characteristics of the group members (we have various ethnicities: Malay, Chinese and Indian). I took this opportunity to make myself comfortable with others, so a specific kind of adjustment must be made to make sure the group member [were] well-functioned....We tried to understand each other...this is very important to make the activity successful. (JR22-2/2/2018)

\section{Category 5: Internal motivation}

The programme, although [it] has been [completed] in one day, [gave us many benefits] and we felt that such [a] programme needs to be extended, for two or three days. (If conducted) we do believe that we [would be] able to perform well. (JR18-7/3/2018)

This is the first time [that I] became a facilitator [and conducted] a programme [involving] the primary school students. Thus, I felt more confident to handle other programmes afterwards. (JR14$7 / 4 / 2018$ )

\section{Category 6: Communication skill}

Our team not only [focused] on the day of the programme, but also before starting the event, whereby we need to meet (for meeting) to make sure the proposed programme is smoothly done....If [I am not] mistaken, at least 3-4 times, meetings were done before it started....Also, two discussions were held in finalising journal writing....In conclusion, there were many meetings done in completing the camp...all these have contributed to...an important skill which is [the] communication skill (verbal and non-verbal communications). (JR9-3/4/2018)

As a facilitator in the programme, I was able to polish my English communication [skills]. (JR11$11 / 3 / 2018$ ) 


\section{Theme 2: Leadership Skill}

Leadership is the ability of an individual or organisation to lead or guide people towards common goals and visions; it is an important attribute of medical professionalism in Malaysia.

\section{Category 7: Teamwork}

Very clear, leadership is among the important skills we [were] able to develop. Handling meetings, proposal defence and communicating with students and school authority was among [events that needed] leadership skills....and all these we got from the event. (JR16-3/3/2017)

Besides, I also [experienced] managing a programme and teamwork among committee members is very important. (JR4-7/4/2017)

Throughout the programme, we have developed a good friendship among us [regardless] of different [ethnicities]. (JR18-7/4/2017)

\section{Theme 3: Scientific Skills}

Scientific skill is important to medical students. The theme of scientific skill was represented by proposal writing skills.

\section{Category 8: Proposal writing skill}

I told the truth, before this I haven't [written] any kind of proposal (during studying at school). When implementing this programme, I got a specific skill in proposal writing. In addition, I was requested to lead this task (writing proposal) and God-willing, I have done the best one. I felt that I have learnt a good knowledge and skill about this (writing proposal) when I was here (in English motivational champ). (JR13-2/2/2017)

\section{DISCUSSION}

The study contributed several important findings that supported the outcome of CPP in the development of professionalism and basic skills among first-year medical students. The evidence shows that personal skills are essential for medical students in order to complete their study properly. This is consistent with a study that found such components are one of the most significant components that such groups should have (22).

For that reason, we assumed that both domains were closely related with each other since it has been recognised as a main contributor in developing basic skills in professionalism. This evidence has supported other previous studies $(1,5-6)$. As concerned by scholarly medical educationists, a good medical doctor must possess various kind of personal skills. This is consistent with the suggestion of this present study, where time management, self-management, selfconfidence, social adjustment, internal motivation and communication skills are important characteristics to increase their professionalism. Although these skills may not have been adopted solely as a result of the CPP, the skills themselves are crucial for these groups of students (23).

The importance of communication skill in students' lives is a fact. As future professional doctors, they will engage in various activities in which communication skills are a part of the learning style. Therefore, possessing this feature at the early stage of their career path is reasonable for them. This evidence is consistent with a previous studies (23-24).

Internal motivation is crucial for the success of all individuals. For medical students who are in the early stages of studying, this feature is regarded as a key role to tackle negative effects on their psychological well-being (25). For that reason, it is seen as reasonable if these groups of students develop internal motivation from any 
activity, including CPP (8). Possessing communication skills is necessary to foster career pathways. It includes introductory skills, questioning skills, listening skills and negotiation skills. Thus, one who is studying must absorb such skills from any activity $\mathrm{s} / \mathrm{he}$ joins. In the context of the present study, the evidence supports the statement that first-year medical students have tried to instil in themselves the communication skills of introduction, questioning and listening through the CPP. This is consistent with the previous study on the similar domain (26). Additionally, as a newcomer to the field of medical training, they require such knowledge and skills to increase their level of confidence and comfortability during their study (10).

Undoubtedly, leadership skills are important factors in developing the professionalism for any profession, especially those in the medical training field. By acquiring these skills, a medical student can follow their path of study in a proper manner (27). For this reason, it is logical that firstyear medical students develop this feature through the use of CPP.

Having scientific skills is also important to determine the success of a medical training. This is because these skills are used broadly, whether in clinical or non-clinical domains, in the duration of the study. Thus, it is reasonable if such groups tackle these skills during the first year of the study (23).

Despite previous results, this study has limitations that must be focused on for future study. First, the present study has used only first-year medical students from a single medical school, leading to a limitation of interpretation context. Thus, it is suggested that future studies recruit different year levels and institutions in order to ensure that study findings are broader and deeper. Secondly, this study applied a total qualitative approach as its research design. Thus, the research findings cannot be expected to represent other populations. As such, similar studies should be conducted quantitatively to verify the features of professionalism obtained from this study.

\section{RECOMMENDATION}

This study revealed that the CPP is significant to develop professional basic skills of medical training. Hence, community placement programmes are not only crucial to maintaining the medical curriculum but they are also in need of revision from time to time in order to ensure consistency with the changes of professional basic skills among medical students.

\section{CONCLUSION}

This study was able to identify three themes and eight categories regarding contribution of CPP to professional basic skills of medical training. Results indicated that CPP is an essential platform for medical students on the path to developing professionalism.

\section{ETHICAL APPROVAL}

The study was conducted after approval by the USM ethic committee (USM/ $\mathrm{JEPeM} / 15040152)$.

\section{ACKNOWLEDGEMENTS}

The authors express a high level of gratitude to all participants of the study for their support in completing this work. The author did not receive any kind of financial support to complete this study.

\section{REFERENCES}

1. Ohta R, Ryu Y, Sano C. The contribution of citizens to community-based medical education in japan: a systematic review. Int J Environ Res Public Health. 2021;18(4):575. https://doi.org/10.3390/ijerph18041575 
2. Weller-Newton JM, Kent F. Community health placements for junior medical and nursing students for interprofessional learning. J Interprof Care. 2021;35(2):3169. https://doi.org/10.1080/13561820.2020.1 760803

3. Al-Rumayyan A, Van Mook WNKA, Magzoub ME, Al-Eraky MM, Ferwana M, Khan MA, et al. Medical professionalism frameworks across non-Western cultures: a narrative overview. Med Teach. 2017;39(sup.1):S8-14. https://doi.org/10.10 80/0142159X.2016.1254740

4. Mat Nor MZ, Yusoff MSB, Ismail MAA. The patterns of professional identity development among medical graduates of a SPICES curriculum simplified thematic engagement of professionalism scale (STEPS) view project rethinking education environment: the clinical education environment framework view project. 2017 [cited 2020 Mar 24]. Available from: https:// doi.org/10.21315/eimj2017.9.4.6

5. Goodall J. Beyond the ward and waiting room: a community-based non-clinical placement programme for Australian medical students. Med Teach. 2012;34(12):1070-4. https://doi.org/ 10.3109/0142159X.2012.719655

6. Mat Pa MN, Ab Rahman A, Abdul Rahim AF, Yusoff MSB, Yaacob NA. Building professional qualities through a community placement programme for medical students. Education in Medicine Journal. 2011;3(1):60-2.

7. Abd Rahman A, Yusoff MSB, Yaacob NA, Ahmad A, Mat Pa MN. Experience from a community placement programme for medical students. Education in Medicine Journal. 2009; 1(1):1.
8. Yusoff MSB, Rahim AFA, Pa MNM, Rahman AA, Ibrahim MI, Jalal MIA, et al. Impacts of a community-academic partnership program facilitated by medical students on a student community: a reflection on MySTAR. Procedia - Soc Behav Sci. 2014;116:734-8. https://doi. org/10.1016/j.sbspro.2014.01.289

9. Mat Nor MZ, Yusoff MSB, Ismail MAA. The patterns of professional identity development among medical graduates of a SPICES curriculum. Education in Medicine Journal. 2017;9(4):51-61. https://doi. org/10.2135/eimj2017.9.4.6

10. Jozaghi E, Yake K, Maynard R, Blyth S. The role of medical students' training and community placement as a tool to enhance medical education in Canada. Journal of Substance Use. 2019;24(1):1-3. https://oi. org/10.1080/14659891.2018.1510051

11. Ahmad A, Bahri Yusoff MS, Zahiruddin Wan Mohammad WM, Mat Nor MZ. Nurturing professional identity through a community based education program: medical students experience. J Taibah Univ Med Sci. 2018;13(2):113-22. https://doi. org/10.1016/j.jtumed.2017.12.001

12. Giorgi A. The descriptive phenomenological psychological method. Journal of Phenomenological Psychology. 2016;43(1):3-12. https://doi.org/10.1163/156916212X632934

13. O’Reilly M, Parker N. "Unsatisfactory saturation": a critical exploration of the notion of saturated sample sizes in qualitative research. Qual Res. 2013;13(2):190-7. https://doi. org/10.1177\%2F1468794112446106 
14. Guest G, Bunce A, Johnson L. How many interviews are enough? an experiment with data saturation and variability. Field Methods. 2006;18(1):59-82. https://doi. org/10.1177/1525822X05279903

15. Strauss AL, Corbin JM. Grounded theory procedures and techniques. Basics Qual Res. 1990;13(1):1-21.

16. Maykut PS, Morehouse RE. Part I building a philosophic foundation for qualitative research. In: Beginning qualitative research: a philosophic and practical guide. UK: Routledge; 1994. https://doi. org/10.4324/9780203485781

17. Creswell JW, Miller DL. Determining validity in qualitative inquiry. Theory Into Pract. 2000;39(3):124-30. https://doi. org/10.1207/s15430421tip3903_2

18. Strauss A, Corbin J. Basics of qualitative research: grounded theory procedures and techniques. 2nd ed. California: Sage; 1990.

19. Corbin J, Strauss A. Basics of qualitative research: techniques and procedures for developing grounded theory. 3rd ed. California: Sage; 2008.

20. Cresswell JW, Cresswell JD. Research design: qualitative, quantitative, and mixed methods approaches. 5th ed. California: Sage; 2018.

21. Packer-Muti B. A review of Corbin and Strauss' basics of qualitative research: techniques and procedures for developing grounded theory. The Qualitative Report. 2009;14(2):140-3. https://doi. org/10.46743/2160-3715/2009.2838
22. Brinkman DJ, Tichelaar J, Graaf S, Otten RHJ, Richir MC, van Agtmael MA. Do final-year medical students have sufficient prescribing competencies? A systematic literature review. Br J Clin Pharmacol. 2018;84(4):615-35. https://doi.org/10.1111/ bcp. 13491

23. Nor MZM. Contribution of faculty developmental programmes to professional identity development of medical educators in Malaysia: a phenomenological study. J Taibah Univ Med Sci. 2019;14(4):324-31. https://doi.org/10.1016/j.jtumed.2019.06.001

24. Haber RJ, Lingard LA. Learning oral presentation skills. J Gen Intern Med. 2001;16(5):308-14. https://doi.org/10.1046 /j.1525-1497.2001.0023

25. Yusoff MSB, Abdul Rahim AF, Baba AA, Ismail SB, Mat Pa MN, Esa AR. Prevalence and associated factors of stress, anxiety and depression among prospective medical students. Asian J Psychiatr. 2013;6(2):12833. https://doi.org/10.1016/j.ajp.2012.09.012

26. Mat Nor ZM, Yusoff SBM, Abdul Rahim FA. Characteristics of mentoring programmes in the early phase of medical training at the Universiti Sains Malaysia. J Taibah Univ Med Sci. 2017;12(4):343-8. https://doi.org/10.1016/j.jtumed.2017.01.003

27. Roslan NS, Yusoff MSB, Ahmad AF, Mohd Hussin ZA. Together we stand, divided we fall: interprofessional collaborative practice competencies from Malaysian medical professionals' perspectives. J Taibah Univ Med Sci. 2016;11(6):533-40. https://doi. org/10.1016/j.jtumed.2016.09.001 